\title{
A TRANSIÇÃO DOS EX-CATADORES DO LIXÃO ÀS COOPERATIVAS DE TRIAGEM: UM PROCESSO EMANCIPATÓRIO DE INCLUSÃO SOLIDÁRIA NO MUNICÍPIO DE PELOTAS-RS
}

\author{
Sandro de Castro Pitano \\ Universidade Federal de Pelotas, Instituto de Ciências Humanas \\ Pelotas, RS, Brasil \\ scpitano@gmail.com \\ Rosa Elena Noal \\ Universidade Federal de Pelotas, Instituto de Ciências Humanas \\ Pelotas, RS, Brasil \\ rosa.noal@gmail.com
}

\begin{abstract}
RESUMO
O artigo analisa o processo de transição dos catadores do lixão para o trabalho cooperado em cooperativas de triagem de resíduos sólidos no município de Pelotas-RS, observando conjuntamente os benefícios ambientais e a inclusão social dos sujeitos. A triagem de resíduos sólidos é uma atividade fundamental para a diminuição da poluição ambiental, além de integrar geração de renda e inclusão social na perspectiva da autogestão solidária. A metodologia procedeu por meio da investigação bibliográfica, análise documental e entrevistas semiabertas com quatro cooperados, ex-catadores do lixão, visando compreender os impactos da transição nos aspectos sociais e econômicos junto aos mesmos. A análise dos dados revelou que o processo de transição representou uma conquista pessoal e coletiva dos trabalhadores e que a organização em cooperativas foi uma alternativa positiva de profissionalização, inclusão e reconhecimento social, proporcionando melhores condições de vida e trabalho.
\end{abstract}

Palavras-chave: Inclusão social. Cooperados. Cooperativas de triagem. Lixão. Resíduos sólidos.

\section{THE TRANSITION OF EX-COLLECTORS FROM THE DUMP TO THE SORTING COOPERATIVES: AN EMANCIPATORY PROCESS OF SOLIDARITY INCLUSION IN THE MUNICIPALITY OF PELOTAS-RS}

\begin{abstract}
The article analyzes the process of transition from waste pickers to cooperative work in solid waste sorting cooperatives in the city of Pelotas-RS, jointly observing the environmental benefits and social inclusion of the subjects. Solid waste sorting is a fundamental activity for the reduction of environmental pollution, besides integrating income generation and social inclusion in the perspective of self-management. The methodology was carried out through bibliographic research, documentary analysis and semi-open interviews with four cooperators, former garbage collectors, aiming to understand the impacts of the transition on the social and economic aspects of the same. The analysis of the data revealed that the transition process represented a personal and collective achievement of the workers and that the organization in cooperatives was a positive alternative of professionalization, inclusion and social recognition, providing better living and working conditions.
\end{abstract}

Keywords: Social inclusion. Cooperated. Sorting cooperatives. Dumping ground. Solid waste.

\section{INTRODUÇÃO}

Este artigo analisa a trajetória de transição dos catadores do lixão para as cooperativas de triagem de resíduos sólidos no município de Pelotas-RS, ocorrida a partir de 2012. A publicação da Lei 12.305/10 que estabeleceu a Política Nacional Resíduos Sólidos (PNRS) exigiu o gerenciamento ambientalmente adequado dos resíduos, implicando no encerramento das atividades do lixão municipal que funcionou no período compreendido entre os anos de 1986 e 2012 (nos últimos anos, foi transformado e operava 
como aterro controlado). Como destacam Sant'Ana e Metello (2016, p.29), "os principais elementos inaugurados pela nova legislação foram a obrigatoriedade de entes públicos elaborarem planos de resíduos sólidos, fecharem lixões e implementarem a coleta seletiva", além de ter a PNRS incorporado "a inclusão de catadores de materiais recicláveis como sua parte fundamental". A migração para as cooperativas de triagem de resíduos sólidos, prevista na Lei 12.305/10, representou uma alternativa promissora para os catadores, proibidos de exercer sua atividade juntamente com o lixão onde atuavam.

O célere desenvolvimento da urbanização, juntamente ao consumo crescente de produtos descartáveis, provocou grande aumento do volume e diversificação dos resíduos gerados. Essa crescente geração de resíduos e sua deposição inadequada são grandes problemas ambientais da atualidade, envolvidos em uma conjuntura delicada e de abrangência complexa. As questões ambientais, como destaca Gonçalves (1996, p. 140) se revestem de complexidade devido ao fato de estarem inseridas "na interface da sociedade com o seu-outro, a natureza". Nessa teia complexa, a atuação dos catadores em conjunto com o poder público torna-se fundamental para um gerenciamento sustentável e seguro desses materiais.

Os ex-catadores, sujeitos dessa pesquisa, são agentes ambientais que atuam diretamente na coleta e na triagem de recicláveis, contribuindo para evitar a formação de lixões. Importante para a questão ambiental, ao mesmo tempo se consolida como atividade econômica integradora de aspectos como geração de renda e inclusão social. Diante da necessidade de mudança imposta pela legislação, muitos dos ex-catadores, cujo quantitativo variava entre trinta e setenta pessoas, aproximadamente, se organizaram em associações e logo após em cooperativas. De acordo com os princípios que regem as cooperativas de trabalhadores, os mesmos são proprietários da empresa e participam em condições de igualdade nas decisões da gestão (autogestão), independentemente do montante da sua participação no capital (BIRCHALL, 1997). Portanto, a cooperativa constitui "um ambiente em que trabalhadores e trabalhadoras assumem a cooperação de maneira livre e participativa, no qual se geram processos relacionais, produtos, técnicas e metodologias não convencionais" (ADAMS et al., 2011, p. 16).

O foco principal é a forma de inserção social desses ex-catadores que como cooperados compõem um importante grupo com razoáveis condições de estabilidade e renda. Por caminhos dialéticos, o processo revela um movimento que parte da precarização do trabalho e conduz, graças à capacidade criativa, ao estabelecimento de relações solidárias com potencial emancipador. Nessa espécie de relação entre inservíveis: pessoas (catadores) e objetos (material reciclável), emergem sujeitos que executam um trabalho de proteção ambiental e contribuem para a gestão dos resíduos sólidos no município. Como afirma Ferreira (2015, p. 106) "os grupos sociais, mesmo em posições de subalternidade, são capazes de articular suas próprias estratégias de escalas de ação". A cooperação consolida a atuação dos catadores nas atividades da coleta seletiva, triagem, classificação, processamento e comercialização dos resíduos, contribuindo de forma significativa para a cadeia produtiva da reciclagem.

Segundo Andrade (1981), catadores são um grupo de consumidores de resíduos, de detritos e de restos daquilo que é gerado por uma minoria que detém o controle dos meios de produção. Desde o ano 2002 os catadores foram reconhecidos formalmente como categoria profissional, conforme a Classificação Brasileira de Ocupações ( $\mathrm{CBO}$ ) do então Ministério do Trabalho e Emprego. Através da efetivação de uma lei específica para o tratamento de resíduos sólidos regulamentou-se as formas de redução, reutilização e reciclagem de resíduos até a sua disposição final ambientalmente adequada. De acordo com Magera (2003) a reciclagem vem se apresentando como uma alternativa social e econômica, processando milhões de toneladas de lixo produzido diariamente pelos grandes centros urbanos espalhados pelo mundo.

Considerando esse processo de transição vivenciado no município de Pelotas-RS, a pesquisa objetivou caracterizar a situação socioeconômica dos ex-catadores de materiais para reciclagem que atuavam no lixão no município de Pelotas-RS, visando conhecer melhor o processo de mudança pelo qual passaram e os impactos sociais e ambientais da transição. Portanto, buscou-se analisar os impactos dessa mudança na vida dos ex-catadores do antigo lixão. Compreendendo e verificando a situação socioeconômica dos trabalhadores, agora na categoria de cooperados, enfocou as relações entre lixo, reciclagem e inserção social, coletando dados por meio de entrevistas com quatro sujeitos vinculados a duas cooperativas. Ao caracterizar a situação dos ex-catadores nos aspectos social e econômico, também buscou-se compreender o que representou para eles o processo de transição e quais são as suas perspectivas para o futuro. A pesquisa possibilitou uma breve análise comparativa entre as

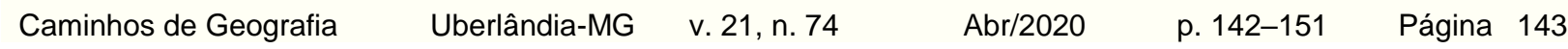


condições enfrentadas no lixão e nas cooperativas, enfatizando os impactos resultantes da mudança na vida dos sujeitos.

Para realizar as entrevistas, foi preciso selecionar cooperativas que tivessem em seu quadro cooperados que atuaram no lixão do município e duas se enquadraram neste quesito. As entrevistas semiabertas foram baseadas em um roteiro estruturado pelos entrevistadores e aplicadas junto aos cooperados na sede das cooperativas, ao longo do ano de 2017. Previamente, foi realizado um teste piloto e visitas periódicas às instituições para promover a integração entre pesquisadores e entrevistados. O roteiro previa quinze perguntas, as quais foram aprofundadas ao longo das visitas e conversas informais com cada cooperado. Essa forma de entrevista, complementada pelos diálogos informais e observações mostrou-se satisfatória e apropriada à obtenção dos dados necessários à compreensão do processo de transição.

$\mathrm{Na}$ sequência o texto aborda as diferentes formas de disposição de resíduos sólidos (lixão, aterro controlado e aterro sanitário) no bojo da legislação pertinente, delineando suas implicações no município de Pelotas-RS. A seguir, analisa o processo de transição vivenciado pelos ex-catadores, do lixão às cooperativas de triagem, caracterizando as duas cooperativas onde atuam os sujeitos entrevistados (cooperativas $\mathrm{X}$ e $\mathrm{Y}$ ). Adentrando nas entrevistas e explorando os diálogos com os sujeitos, busca dimensionar suas condições sociais e econômicas em meio à situação de cooperados, estabelecendo comparações com o período de trabalho no lixão. Também destaca o que os entrevistados consideram como perspectiva de futuro. Por fim, desenvolve as considerações finais, onde reúne as reflexões extraídas do conjunto de entrevistas e diálogos, dos documentos (leis) e da bibliografia consultados.

\section{A DISPOSIÇÃO DOS RESÍDUOS SÓLIDOS: LIXÃO, ATERRO CONTROLADO E ATERRO SANITÁRIO}

A crescente quantidade de lixo é um problema a ser pensado pelas administrações públicas e a sociedade como um todo. O volume de resíduos gerados vem aumentando nos grandes centros urbanos em consequência do crescimento acelerado e desordenado das cidades, juntamente com o consumismo imposto pela cultura capitalista e promovido pelo aparato publicitário. Conforme a Pesquisa Nacional de Saneamento Básico de 2008, do Instituto Brasileiro de Geografia de Estatística (IBGE), no Brasil são geradas diariamente 240 mil toneladas de resíduos urbanos. Portanto, cada brasileiro gera em torno de $1,4 \mathrm{~kg}$ de resíduos por dia, dos quais $60 \%$ são orgânicos e $40 \%$ são materiais recicláveis ou rejeitos (IBGE, 2008)

Para Baquero e Cremonense (2006), uma das características essenciais do desenvolvimento sustentável, ao contrário da forma tradicional de desenvolvimento que reflete a cultura capitalista, é considerar ambiente e sociedade como um conjunto. Diz respeito não apenas à proteção do meio ambiente, mas incorpora as pessoas, suas necessidades e como elas podem ser satisfeitas equitativamente.

Segundo ABNT (1985) entende-se como lixo o resto das atividades humanas, que não possuem utilidade nem valores funcionais ou estéticos para o seu gerador, podendo apresentar-se sob estado sólido, semissólido ou semilíquido. Para a Política Nacional de Resíduos Sólidos (BRASIL, 2010), o rejeito é o material indesejável para o qual ainda não há tecnologia ou viabilidade econômica para tratamento, reuso ou reciclagem, e o resíduo é o material indesejável que pode receber tratamento e reciclagem. A destinação final ambientalmente adequada dos resíduos inclui a reutilização, a reciclagem, a compostagem, a recuperação e o aproveitamento energético ou outras destinações admitidas pelos órgãos competentes. A distribuição ordenada de rejeitos em aterros, observando normas operacionais específicas, evita danos ou riscos à saúde pública e ainda minimiza os impactos ambientais.

Conforme Pereira Neto (2011, p. 79), a Política Nacional de Resíduos Sólidos "contempla instrumentos como a logística reversa e fomenta a participação dos catadores de materiais recicláveis nos sistemas de gestão de resíduos sólidos como forma de inclusão social e econômica". Destacam-se três aspectos importantes para a ressignificação da gestão de resíduos: a responsabilidade solidária, a priorização de cooperativas e outras associações de gestão dos resíduos e a conscientização ambiental como projeto a ser defendido e implementado de forma permanente. O lixo constitui uma preocupação ambiental mundial, especialmente em grandes centros urbanos de países subdesenvolvidos. Atualmente no Brasil existem três formas de disposição final dos resíduos sólidos: lixões, aterros controlados e aterros sanitários. 
Os lixões são enormes áreas a céu aberto utilizadas como depósito, sem nenhum tipo de proteção do solo. É uma forma inadequada de disposição final dos resíduos sólidos, pois se caracteriza como um descarte sem a adoção de cuidados com o meio ambiente. Os lixões não possuem tratamento de efluentes líquidos, como o chorume (líquido escuro que escorre dos resíduos sólidos) que pode contaminar o solo e se infiltrar até o lençol freático causando graves problemas ambientais. Além destes impactos ambientais existe um importante impacto social, pois é muito comum encontrar a presença de catadores nesses locais. Famílias de baixa renda que retiram dos lixões seu sustento, assumindo riscos de se machucarem com objetos cortantes que são descartados de forma irregular e sofrerem contaminação por contato ou mesmo por ingestão de alimentos.

Aterro controlado, segundo a NBR 8849/85 é uma técnica de disposição de resíduos sólidos urbanos no solo, sem causar danos ou riscos à saúde pública e à segurança, minimizando os impactos ambientais. Esse método utiliza princípios de engenharia para confinar os resíduos, cobrindo-os com uma camada de material inerte na conclusão de cada jornada de trabalho. Para construção de um aterro controlado procura-se, primeiramente, isolar a área de um antigo lixão. Esse isolamento é feito com cobertura impermeável de manta plástica, além de alguns procedimentos adicionais como cerca de isolamento, sistema viário interno, controle na portaria e, em alguns casos, sistema de pesagem de resíduos acrescido de sistema informatizado de processamento de dados.

Nos aterros controlados o biogás é queimado, assim como uma parte do chorume é capturado por bombeamento e recolhido para a superfície. Com essa técnica de disposição produz-se, em geral, poluição localizada, não havendo impermeabilização de base (comprometendo a qualidade do solo e das águas subterrâneas), nem sistema de tratamento de percolado (chorume mais água de infiltração) ou de extração e queima controlada dos gases gerados. O termo aterro controlado começou a ser utilizado para denominar os aterros "não sanitários", os quais apresentam algumas falhas ou faltas, tais como impermeabilização do fundo, não recolhimento e tratamento do percolado e coleta dos gases produzidos. O aterro controlado pode ser compreendido como uma solução intermediária entre o aterro sanitário e o lixão, como uma tentativa de tentar transformar os lixões em aterros sanitários.

O aterro sanitário representa uma disposição final ambientalmente adequada dos resíduos sólidos. Souza (2000) afirma que aterros sanitários correspondem ao método de disposição final de resíduos no solo sem causar danos ao ambiente ou à saúde pública. Utiliza processos de engenharia no confinamento dos resíduos, que são dispostos em camadas e cujo escoamento de líquidos e emissão de gases são controlados. Como obra de engenharia pautada em princípios da Associação Brasileira de Normas Técnicas (ABNT), no aterro sanitário os rejeitos são depositados em local que passou por processos de nivelamento, impermeabilização e selagem, impedindo o vazamento de chorume para o subsolo.

Entre os desafios e atribuições do poder público, especialmente o municipal, está a formulação de políticas públicas e programas de educação ambiental permanentes. Políticas que estimulem a participação das comunidades nos processos de planejamento, gestão urbana e saneamento, de forma estratégica. Como lembra Santos (2002, p. 253) "a produção do meio técnico-científico obriga a uma reinterpretação qualitativa do investimento público, em função dos círculos de cooperação" que se formam de maneira complexa em uma região. O município de Pelotas integra uma minoria que conseguiu cumprir a Política Nacional de Resíduos Sólidos. O lixão foi fechado e transformado em aterro controlado visando à implantação futura de uma praça de lazer para a população.

\section{O PROCESSO DE TRANSIÇÃO: DE CATADORES A COOPERADOS}

Segundo Figueiredo (2009), cooperar é unir-se a outras pessoas para o enfrentamento conjunto das situações adversas, transformando-as em oportunidades e situações de bem-estar econômico e social. O cooperativismo surge como um movimento internacional cujo objetivo é romper com a cultura do individualismo por meio da cooperação entre as pessoas. Pessoas unidas com objetivos econômicos e sociais comuns, que como sócias de uma cooperativa recebem as vantagens advindas da atuação de todos os associados. $O$ trabalho nas cooperativas propõe uma forma participativa para que cada pessoa obtenha o seu sustento, tornando-se capaz de regular a própria produção e a distribuição dos ganhos. Compreende, portanto, "um modo alternativo de produção e distribuição capitalista, voltado para aqueles que estão fora do mercado" (SANTOS et al., 2016, p. 86). 
De acordo com Leite (2009), a formação de cooperativas de reciclagem em diversas regiões do Brasil tem sido objeto de pesquisas que mostram a importância da atividade para mitigar o impacto ambiental dos resíduos sólidos urbanos, por meio do trabalho de coleta seletiva. Ao mesmo tempo, destacam as dificuldades de ex-catadores que começam a se organizar em cooperativas, com o apoio do setor público, privado e da sociedade civil. Como destacam Medeiros e Macedo (2006, p.66) "uma cooperativa de catadores pode desenvolver diferentes ações, visando enfrentar fatores que interferem no processo de negociação de materiais recicláveis", promovendo uma maior "competitividade através do aumento da oferta de materiais recicláveis num volume maior que garanta negociação de preços". Os cooperados são responsáveis pela triagem, acondicionamento, enfardamento e comercialização dos resíduos sólidos descartados pela sociedade. O trabalho cooperativo é de tamanha complexidade e evidencia a conscientização ambiental, técnica e o trabalho coletivo, identificando os cooperados como agentes ambientais. Tudo isso se reflete em autoestima e colabora na luta por reconhecimento, dignidade e inclusão social.

O trabalho com o material reciclável interfere na identificação dos catadores com o seu trabalho e no reconhecimento da sociedade pela ação que desempenham. No ano de 2010, com a promulgação da Lei 12.305/10, o município de Pelotas implantou o Programa de Inclusão Social e Geração de Trabalho e Renda para Famílias de Catadores e incentivou a formação de cooperativas de trabalho formadas por catadores de rua, principalmente por aqueles que retiravam do lixão o sustento de suas famílias. $O$ fortalecimento da organização produtiva dos catadores em cooperativas com base nos princípios da autogestão, da economia solidária e do acesso a oportunidades de trabalho decente representa, portanto, um passo fundamental para a inserção social e o empoderamento dos sujeitos.

Atualmente o município de Pelotas mantém convênio com sete cooperativas que abrigam quarenta e quatro cooperados, subsidiando uma verba mensal de até quinze mil reais por cooperativa. A verba se destina ao atendimento de despesas tais como: previdência social, bolsa-auxílio no valor de quatrocentos reais para cada cooperado, água, luz, telefone, impostos, manutenção, óleo, combustíveis, arame ou cintas de enfardamento e aquisição de equipamentos para a cooperativa como balança, elevador de cargas, esteiras e veículos. A parte social do convênio prevê cursos de formação aos cooperados, participação em seminários e outras atividades culturais e educativas.

Uma empresa terceirizada executa a coleta seletiva no município e repassa o material reciclável para as cooperativas conveniadas que fazem a triagem, enfardamento, armazenamento e por último a comercialização dos resíduos. E exigido que cada cooperativa esteja devidamente regularizada como pessoa jurídica mantendo atualizadas todas as certidões negativas do âmbito municipal, estadual e federal, e também a apresentação de todas as Atas, Balanço, Balancetes e o Balanço Anual. Cada cooperativa é responsável pela gestão mensal administrativo/financeira dos recursos oriundos da agenda financeira repassada, organizando-se contabilmente e prestando contas mensais detalhadas de todas as despesas e investimentos realizados com os recursos do convenio.

As duas cooperativas junto às quais foram entrevistados os sujeitos são denominadas como Cooperativa $X$ e Cooperativa $Y$, caracterizadas a seguir.

A Cooperativa $X$ existe desde 2012 e apresenta como atividade básica a triagem de materiais recicláveis, separação e venda aos intermediários, atingindo uma média de 30 toneladas/mês de resíduos sólidos comercializados. O material recolhido basicamente provém da coleta seletiva do município. O processo, desde a chegada dos resíduos na cooperativa até a comercialização começa com o recebimento do caminhão de coleta seletiva, que é basculhado dentro do galpão e próximo à esteira onde é feita a descarga dos resíduos. $\mathrm{Na}$ esteira inicia-se a etapa de separação e triagem onde são classificados conforme o tipo: metal, plástico, papelão e vidro. Todos os resíduos após classificação são colocados em bags, sendo que plástico e papelão são enviados à prensa hidráulica para formação de fardos que ficam estocados até a comercialização. A cooperativa $X$ ocupa uma área alugada de aproximadamente 700 metros quadrados com um galpão coberto e possui escritório, cozinha e banheiro.

O horário de funcionamento da cooperativa é em turno único e direto das $08 \mathrm{~h} 00 \mathrm{~min}$ às $15 \mathrm{~h} 00 \mathrm{~min}$, de segunda à sexta-feira, mantendo um plantonista nos fins de semana. Cada cooperado possui uniforme de trabalho composto por calça, jaleco e botinas e são devidamente equipados com Equipamentos de Proteção Individual (EPI). No seu quadro atual possui 15 cooperados na faixa etária que varia entre 20 e 70 anos, sendo 8 homens e 7 mulheres. A escolaridade varia entre analfabeto e ensino médio incompleto, predominando o ensino fundamental incompleto. $O$ valor médio do rateio mais a bolsaauxílio varia entre mil e mil e duzentos reais mensais para cada cooperado. A cooperativa é devidamente legalizada, mantendo atualizados todos os documentos necessários para o seu pleno funcionamento.

Caminhos de Geografia $\quad$ Uberlândia-MG $\quad$ v. 21, n. $74 \quad$ Abr/2020 $\quad$ p. 142-151 Página 146


O trabalhador que aderir à cooperativa e adquirir o status de cooperado não é caracterizado como empregado. Embora perante a lei não exista a exigência de que as cooperativas cumpram determinados benefícios aos seus cooperados, tais como férias, seguro desemprego, registro em carteira e $13^{\circ}$ salário, essa cooperativa organiza-se para que todos anualmente recebam 30 dias de descanso como gozo de férias, sem nenhum prejuízo financeiro ao cooperado, pois é mantida sua remuneração mensal normalmente. Outro benefício característico desta cooperativa é um rateio anual como um fundo natalino. Durante o ano os cooperados fazem uma reserva de material que é vendida no final de cada período para ser dividida como benefício de $13^{\circ}$ salário.

A Cooperativa Y foi fundada em 2011 e também apresenta como atividade básica a triagem de materiais recicláveis, separação e venda aos intermediários, atingindo uma média de 18 toneladas/mês. Os resíduos recebidos por esta cooperativa também provêm da coleta seletiva municipal e classificam-se entre metal, plástico, papelão e vidro. Está instalada em uma área alugada de aproximadamente 200 metros quadrados, possuindo um galpão em perfeitas condições hidráulicas e elétricas e contendo rede elétrica adequada para os equipamentos. Possui uma área reservada com refeitório, cozinha e banheiros masculino e feminino e conta com 16 cooperados na faixa etária que varia entre 19 a 59 anos. A escolaridade da maioria é o ensino fundamental incompleto. O processo de recebimento dos resíduos, distribuição, triagem e comercialização não se diferencia entre as duas cooperativas, pois a rotina faz parte de um procedimento padrão a ser seguido.

A Cooperativa Y mantém como valor médio do rateio mais a bolsa-auxílio entre quinhentos e seiscentos reais mensais para cada cooperado. Possui a sua documentação legalizada, mantendo atualizados todos os documentos necessários para o seu pleno funcionamento perante os órgãos federais, estaduais e municipais. Conforme organização própria e sem exigência legal, os cooperados gozam de 30 dias de descanso anual, e contam com o recolhimento da taxa de $11 \%$ para fins de INSS. Esse recolhimento garante um benefício mensal durante a aposentadoria e o recebimento de auxílio-doença em caso de afastamento do serviço por motivo de saúde e licenças, como a maternidade.

A cooperativa funciona seis horas por dia somando trinta horas semanais, seus cooperados trabalham devidamente uniformizados e com os equipamentos obrigatórios para sua proteção (EPI). Em seu sistema organizacional, a cooperativa efetua o controle de atividades por meio de planilhas que descrevem recebimentos dos resíduos e sua comercialização. O material após a triagem na esteira é selecionado e separado em bags que ficam armazenados para posteriormente ir para prensa hidráulica, enfardamento e comercialização.

\section{ASPECTOS SOCIAIS E ECONÔMICOS DOS COOPERADOS}

O trabalho significa para o trabalhador uma forma de afirmar sua identidade por meio de atribuições individuais inseridas por ele na realização da tarefa, explica Dejours (1994). Não é somente uma forma de subsistência, mas também um meio de integração e inclusão social, pois o relacionamento entre pessoas proporciona um sentimento de pertencimento a um grupo. A organização dos catadores em cooperativas foi uma ótima alternativa de conquistar mais renda, profissionalização, inclusão e reconhecimento, além de melhores condições de trabalho. Passando de catadores a cooperados, estes trabalhadores das sobras conseguem resgatar matéria prima para garantir renda, além de contribuir na redução dos gastos públicos, aumentar a vida útil dos aterros sanitários e proteger o meio ambiente.

Para as entrevistas foram selecionados quatro cooperados das duas cooperativas $(X$ e $Y)$ que atuam como conveniadas, escolhidos em função de serem, todos, ex-catadores do lixão do município de Pelotas. Os entrevistados não concluíram o ensino fundamental e a idade varia de 25 a 59 anos. Foram abordados assuntos relacionados à vida pessoal, financeira, profissional bem como a expectativa de vida futura enquanto cooperados. As informações coletadas nas entrevistas foram tratadas de forma qualitativa, como é comum em relatórios de estudos de caso. As observações, anotações e gravações das entrevistas foram transcritas, retratando a história de vida de cada entrevistado, especificamente no período de transição do lixão para as cooperativas. Para realizar as perguntas utilizou-se um procedimento menos formal, com entrevista semiaberta feita diretamente pelos pesquisadores e registradas por meio de gravador digital. Os entrevistados, três homens e uma mulher, estão identificados por letras: A e B (Cooperativa X) e C e D (Cooperativa Y).

Na cooperativa $X$, conforme dia e hora previamente combinados, o cooperado $A$ (45 anos) foi o primeiro entrevistado. Relatou que trabalha há sete anos na cooperativa e que hoje possui renda e vida dignas: 
Estou na cooperativa desde que foi fundada. Anteriormente eu trabalhava em uma associação de catadores, mas minha renda não dava para pagar as contas porque eu ganhava muito pouco e trabalhava muito. Na época da associação eu não tinha INSS e se ficasse doente ficava sem dinheiro. Antes da associação eu trabalhei no lixão e lá sim ganhava bem mais do que na associação. O trabalho no lixão era muito difícil porque no meio do lixo às vezes vinha agulha e caco de vidro que cortava a gente $e$ também eu catava de noite para vender o material de dia, era bem difícil. Hoje estou muito feliz com a cooperativa, dela sustento toda minha família e ganho um dinheiro bom que dá até para ter uns luxos de vez em quando. (Cooperado $A$ ).

A renda mensal de A gira em torno de mil e quinhentos reais, pois exerce um cargo de coordenação. Segundo dados da entrevista, ele supre suas necessidades básicas e de sua família e ainda reserva um valor mensal para diversão. Relata ainda que como lazer "gosta de fazer um churrasquinho, pescaria e futebol". A sua qualidade de vida após ingressar na cooperativa melhorou sensivelmente, pois passou a ter mais tempo para ficar com a família, para cuidar da casa e ainda conseguiu adquirir bens como um veículo para passear aos finais de semana.

O segundo entrevistado foi B ( 29 anos) que trabalha a 4 anos na cooperativa e também fazia parte da antiga associação de catadores. Ele explica:

Quando entrei para cooperativa há 4 anos, eu não tinha emprego, eu vinha da associação onde eu era explorado. Eu vim do lixão era catador de lixo e passava muito trabalho, com chuva e frio além de ter que conviver com ratos e urubus que ficavam na volta da gente. A minha história de vida no lixão é desde a barriga da minha mãe, quando ela estava grávida já catava no lixão, depois quando nasci e completei 3 anos ela já me levava junto. Minha infância foi toda dentro do lixão. Hoje graças a Deus tenho a minha casa e meus móveis e meu trabalho é muito melhor. (Cooperado B).

$\mathrm{Na}$ cooperativa, B tem uma renda superior a mil reais mensais, sente-se qualificado sobre o conhecimento do material que tria porque participou de várias palestras e cursos. Está concluindo as obras da sua casa própria, pois é noivo e pretende casar e manter sua família. Com seu horário de trabalho diurno consegue frequentar uma academia e nas horas vagas gosta de ver televisão e cuidar da casa.

$\mathrm{Na}$ cooperativa $\mathrm{Y}$ as entrevistas foram feitas em dois momentos, no primeiro dia com a cooperada $\mathrm{C}$, (59 anos) a que possui mais idade entre todos os cooperados. Trabalha há cinco anos nesta cooperativa e antes trabalhou por dois anos em outra cooperativa. Em suas palavras:

Estou na cooperativa desde que abriu, hoje trabalho em um galpão coberto, no tempo de lixão trabalhava a noite e na rua, era muito ruim. Hoje tenho minha casinha própria com as minhas coisinhas dentro de casa. Trabalho de dia e tenho mais tempo livre, consegui comprar roupas e roupa de cama, não passo mais frio. Hoje tenho tempo para cuidar da minha casa e vejo TV e a noite estou em casa. Fico mais tranquila porque é descontado INSS do meu dinheiro e estou perto de me aposentar. Espero que os próximos anos passem rápido para eu me aposentar. (Cooperada C).

C recebe em média seiscentos reais por mês, procura usar seus rendimentos para alimentação e aquisição de medicamentos. Mora em um bairro afastado da cooperativa e necessita do transporte urbano para o seu deslocamento.

No segundo dia na cooperativa $Y$ o entrevistado foi $D$, um jovem de 25 anos, ex-jogador de futebol e que trabalha desde a fundação da cooperativa, há cinco anos. Ele explica:

Trabalhei no lixão em noites frias e escuras. Era um trabalho triste para um adolescente eu tinha que catar material naquela escuridão para poder vender no outro dia. Parecia que eu fazia parte de um mundo diferente porque passava muito tempo em cima do lixão. Hoje na cooperativa tenho um teto que me protege da chuva e do frio e ainda trabalho só durante o dia. (Cooperado D).

D possui, assim como $\mathrm{C}$, uma renda mensal de aproximadamente seiscentos reais, mora em uma residência cedida por um familiar. Relata que sua situação financeira após ser cooperado melhorou, pois conseguiu adquirir eletrodomésticos para sua casa e ainda consegue fazer uma reserva para a diversão nos fins de semana, que é jogar futebol. Após ter saído do lixão ingressou no futebol em um time fora de Pelotas, mas por sentir falta da sua família largou tudo e voltou. Como possui pouca escolaridade não conseguiu trabalho, procurou a cooperativa próxima de sua casa e conseguiu tornarse um cooperado. 
Nota-se que existe uma tendência dos cooperados perceberem a importância do trabalho de coletar, separar e reciclar. Continuam se preparando e capacitando para adquirir maiores informações técnicas, entendendo que podem e devem se qualificar profissionalmente. Nesse movimento, acabam imprimindo um encontro entre saberes técnicos e populares, sem que, necessariamente, um predomine sobre o outro. De forma geral pode-se afirmar que todos os entrevistados que vieram do lixão para se tornar cooperados tiveram uma significativa melhora na sua vida profissional. Inicialmente se engajaram no trabalho como cooperados por falta de opção, pois possuem baixa escolaridade. Em contrapartida, perceberam que é possível sobreviver dignamente do material reciclável e ainda colaborar com a sociedade e o meio ambiente, considerando-se agentes ambientais.

\section{PERSPECTIVAS DE FUTURO DOS COOPERADOS}

O processo de separação de material reciclável é imprescindível para a sustentabilidade ambiental. As cooperativas, ao mesmo tempo em que consolidam oportunidades de trabalho e inclusão social, são organizações úteis ao processo industrial, pois diminuem os gastos das indústrias. Elas são responsáveis por efetuar a separação, classificação e enfardamento dos resíduos, atividades executadas por cooperados na estrutura física de cada cooperativa. A reciclagem é viável tanto para o meio ambiente quanto para a qualidade de vida da sociedade, mas principalmente para a inserção social dos cooperados que trabalham como agentes do meio ambiente.

Baseado nos relatos das entrevistas nota-se que os cooperados são unânimes em afirmar que executam um trabalho digno, embora pouco reconhecido e valorizado. Afirmam também que comparando o trabalho executado antes de participar da cooperativa e o que exercem hoje, sem dúvida a situação melhorou muito. Principalmente porque trabalham de dia, com carga horária específica e em local fechado. É notável ao visitar os galpões, tanto na cooperativa $X$ como na cooperativa $Y$, a existência de um ambiente familiar e ao indagar os entrevistados sobre este assunto eles relatam que realmente convivem como se fossem uma família. A parceria entre eles ultrapassa o fato de serem colegas de trabalho, consolidando uma preocupação coletiva para que todos se sintam bem no mesmo ambiente. As duas cooperativas promovem todos os meses um dia para confraternização dos cooperados, aproveitando para comemorar os aniversariantes do mês em um almoço coletivo.

Com relação ao aspecto financeiro, hoje como cooperados estão mais satisfeitos do que quando eram catadores. Obviamente, todos gostariam de receber mais e suas perspectivas são de que o material reciclável se torne mais valorizado. Gostariam que no futuro sua profissão fosse melhor reconhecida

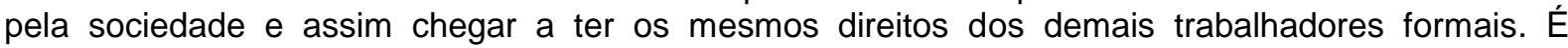
interessante ressaltar que pelos relatos percebe-se o entendimento de que desenvolvem uma atividade rejeitada socialmente por trabalharem com o lixo, ou seja, com aquilo que a sociedade descartou. Ainda que o trabalho executado cause satisfação, os cooperados almejam outras ocupações que possam garantir um maior reconhecimento social e inserção no mercado de trabalho. Alegam que as maiores dificuldades sempre resultaram da falta de acesso à educação e por consequência, de qualificação profissional.

No relato do cooperado $D$ pode-se confirmar essa ideia quando ele diz: "minha vontade é seguir a minha carreira de jogador de futebol, fazer uma faculdade e dar aulas de educação física". Já a perspectiva para o futuro do cooperado B, em suas palavras, é de que "gostaria de terminar o ensino fundamental e fazer um curso profissionalizante de padeiro". A pensa em terminar os estudos quando diz: "quero estudar para terminar o primeiro grau e mostrar para o meu filho como é importante o estudo, pois quero que ele estude". A cooperada C por estar a muitos anos trabalhando e próxima da idade de se aposentar faz o seguinte relato: "não vejo a hora de me aposentar, falta apenas cinco anos, aí vou descansar e aproveitar minha aposentadoria".

Baseado na análise das informações coletadas pode-se afirmar que a maioria dos cooperados, mesmo possuindo baixa escolaridade, administra sua renda de forma a adquirir razoáveis condições de moradia e infraestrutura. Possuem qualidade de vida e apesar das condições econômicas e da baixa escolarização não enfrentam grandes problemas familiares. Colocam a família sempre em primeiro lugar e sustentam a necessidade de mostrar aos seus filhos que vale a pena estudar para que tenham um futuro melhor. Os cooperados alegam que os dois motivos principais para a dificuldade de inserção ao mercado de trabalho são a falta de escolaridade e de capacitação, mas mesmo assim não se sentem excluídos da sociedade. Hoje sentem-se orgulhosos pelo trabalho que executam, conseguem enxergar a importância da sua atividade como agentes ambientais e continuam perspectivando melhorias nos aspectos econômicos e sociais. 


\section{CONSIDERAÇÕES FINAIS}

A pesquisa abordou o processo de transição vivenciado por catadores que atuavam em cima de um lixão, exercendo uma atividade insalubre e desumana, que hoje são cooperados em cooperativas de triagem. Trabalham dentro de um galpão coberto, protegidos das intempéries, garantindo melhor renda e qualidade de vida para si e suas famílias. Sujeitos que lutaram e continuam lutando por uma vida digna nas dimensões econômica, social e afetiva, além da busca pelo reconhecimento daquilo que são e fazem profissionalmente a partir do trabalho com os resíduos. Os cooperados entendem o quanto são importantes para o meio ambiente e começam a compreender que atuam como agentes ambientais. E com isso, poderão demonstrar sua importância para a sociedade, constituindo-se como elementos fundamentais da preservação ambiental.

A preocupação do poder público municipal com a destinação correta dos resíduos sólidos inclui projetos para ascensão das cooperativas e consequentemente dos seus cooperados. $O$ apoio do poder público municipal contribui para que os cooperados se sintam mais valorizados e amparados frente à sociedade. Foi visível nas entrevistas a sensação de que após ingressarem nas cooperativas, emergiu o sentimento de inclusão, de cidadania e de que foram reinseridos na sociedade. Considerando que inclusão é o ato de inserir ou fazer parte de algo, pode-se dizer que a inclusão social evidencia pertencer à sociedade e usufruir dos direitos como cidadão. $O$ aumento da autoestima desses sujeitos é evidenciado em um trecho da entrevista com o cooperado $B$, que afirma o quanto é importante para ele não ser chamado de "catador", mas sim de "cooperado".

Por fim constata-se que os objetivos da pesquisa foram alcançados, sendo possível afirmar que a transição do lixão para as cooperativas resultou em um processo de inserção social. Ao assumirem de forma participativa as mudanças sentem-se como atores na construção da sua própria história. Deixaram de ser "catador" para tornar-se "cooperado", ganhando autoestima e desenvolvendo sentimentos de emancipação, liberdade e conquista. Além de interagir com os cooperados, conhecendo e vivenciando o seu dia-a-dia, foi possível constatar que são pessoas humildes, trabalhadoras, lutadoras em busca de uma vida melhor e que hoje se consideram cidadãos. São sobreviventes de um dos piores tipos de trabalho destinados ao ser humano, catando lixo à noite, dividindo o espaço com ratos e urubus. Ainda assim conseguiram superar e melhorar sua qualidade de vida, inserindo-se na sociedade.

Com este processo, inaugurou-se uma lógica que, mesmo inconscientemente, subverte as relações capitalistas de produção e consumo, pois os cooperados controlam o poder decisório, gerem coletivamente a produção e se apropriam dos frutos do próprio trabalho. Pertencendo a um grupo, elaboram uma identidade coletiva em construção permanente, permitindo em meio às tantas dificuldades que continuem sonhando com um futuro melhor.

\section{REFERÊNCIAS}

ABNT - ASSOCIAÇÃO BRASILEIRA DE NORMAS TÉCNICAS. NBR 8849: Apresentação de projetos de aterros controlados de resíduos sólidos urbanos. Rio de Janeiro, 1985.

ADAMS, T., SHOLZ, R. H., CARGNIN. T. M., HOSSEIN, T. S. Tecnologia social e economia solidária: desafios educativos. Revista Diálogo, ํo18, jan-jun/2011 (p. 13-35).

ANDRADE, M. C. de. Geografia Econômica. São Paulo: Atlas, 1981.

BAQUERO, M.; CREMONENSE, D. Capital social: teoria e prática. ljuí: Unijuí, 2006.

BIRCHALL, J. The International Cooperative Movement. Manchester: Manchester University Press, 1997.

BRASIL. Lei Federal no 12.305/2010 - Institui a Política Nacional de Resíduos Sólidos; altera a Lei no 9.605, de 12 de fevereiro de 1998; e dá outras providências. Publicado no Diário Oficial da União - DOU de $03 / 08 / 2010$.

BRASIL. Portaria no 397, de 09 de outubro de 2002. Aprova a Classificação Brasileira de Ocupações - CBO/2002. Disponível em: http://www.mtecbo.gov.br/cbosite/pages/legislacao.jsf. Acesso em 30 out. 2019.

DEJOURS, C. A loucura do trabalho: contribuições da escola dejouriana à análise da relação prazer, sofrimento e trabalho. (2ª ed.). São Paulo, SP: Atlas, 1994. 
FERREIRA, R. N. Democracia e participação: da teoria à prática territorial e às interações escalares. ACTA Geográfica, v.9, n.20, mai./agos./2015 (p. 96-108).

FIGUEIREDO, N. T. Cooperativas Sociais: Alternativa para Inserção. Porto Alegre: Evangraf, 2009.

GONÇALVES, C. W. P. Os (des)caminhos do meio ambiente. $5^{\mathrm{a}}$ ed. São Paulo: Contexto, 1996.

IBGE - Instituto Brasileiro de Geografia e Estatística. Pesquisa Nacional de Saneamento Básico, 2008. Rio de Janeiro: IBGE, 2008. Disponível em: www.ibge.gov.br. Acesso em: 06 out. 2017.

LEITE, P.R. Logística Reversa: meio ambiente e competitividade. 2. ed, São Paulo: Pearson Prentice Hall, 2009.

MAGERA, M. Os empresários do lixo: um paradoxo da modernidade. Campinas: Átomo, 2003.

MEDEIROS, L.F.R.; MACEDO, K.B. Catador de material reciclável: uma profissão para além da sobrevivência? Psicologia \& Sociedade; 18 (2): 62-71; mai./ago. 2006. https://doi.org/10.1590/S0102$\underline{71822006000200009}$

PEREIRA NETO, T. J. A política Nacional de Resíduos Sólidos: os reflexos nas cooperativas de catadores e a logística reversa. Revista Diálogo, no18, jan-jun/2011 (p. 77-96).

SANT'ANA, D.; METELLO, D. Reciclagem e Inclusão Social no Brasil: Balanço e Desafios. In: PEREIRA, B. C. J.; GOES, F. L. (Orgs.). Catadores de materiais recicláveis: um encontro nacional. Rio de Janeiro: IPEA, 2016. (p.21-44).

SANTOS, F. F., FONTES, A. R. M., MORIS, V. A. S., SOUZA, R. L. R. Atores da cadeia de reciclagem: influência e impactos na atividade de triagem de materiais em uma cooperativa de Sorocaba-SP. Revista de Gestão Social e Ambiental - RGSA, São Paulo, v. 10, n. 3, p. 85-101, set./dez. 2016.

SANTOS, M. A natureza do espaço: técnica e tempo, razão e emoção. São Paulo: EDUSP, 2002. (Coleção Milton Santos).

SOUZA, M. T. S. Organização sustentável: indicadores setoriais dominantes para avaliação da sustentabilidade análise de um segmento do setor de alimentação. (Tese) Doutorado em Administração. Fundação Getúlio Vargas, São Paulo, 2000.

Recebido em: 09/10/2019

Aceito para publicação em: 10/02/2020 